KUIENEBERGER-Nobel, E. (1951). J. gen. Microbiol. 5, 525-530.

\title{
The L-cycle: a Process of Regeneration in Bacteria
}

\author{
BY E. KLIENEBERGER-NOBEL \\ The Lister Institute of Preventive Medicine, London
}

SUMMARY: From a study of the mode of production of the L-phase from the bacillary phase and of the reversion of the L-phase into bacilli, by phase-contrast microscopy and in stained preparations, it appears that the L-cycle is a process of regeneration in bacteria.

Previous work (Klieneberger-Nobel, 1949a) on the L-phase in bacterial cultures was based on fixed and stained material. The phase-contrast microscope has made it possible to see significant detail in the living cell; the evidence presented in this paper for the existence of an L-cycle is based on a study by both methods.

\section{METHODS}

The organisms used were: the Morax-Axenfeld bacillus strain '260', Proteus vulgaris, Shigella shigae, strain 'KIR' and the stabilized L-phase of Streptobacillus moniliformis and Fusiformis necrophorus, L 1 'An' and L 'Fair' respectively, both isolated by me in 1949 .

For the study of the living material nutrient agar plates were inoculated and cut into pieces $0.75 \mathrm{~cm}$. square, the inoculated surface was covered with a sterile cover-slip and the whole sealed to slides with paraffin wax. These preparations were examined with a phase microscope fitted with a longdistance condenser; usually at a temperature of $32^{\circ}$, but sometimes room temperature and $4^{\circ}$. Preparations were fixed and stained by the author's Bouin Giemsa method and Robinow's method for nuclear structures (Klieneberger-Nobel, 1950).

\section{OBSERVATIONS}

\section{Morax-Axenfeld bacillus, strain 260}

The strain grew well on serum agar, producing long chains of bacilli. It was always pleomorphic, and produced L-forms freely. However, the production of L-forms was greatly enhanced by the addition of $0.05-0.07 \%$ of glycine

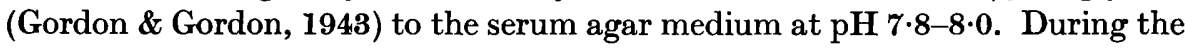
first $2 \mathrm{hr}$. at $32^{\circ}$ no observable change occurs except growth. Soon afterwards the habit of the cultures begins to change; many filaments composed of chains of organisms bend sharply so that the two limbs of the bend lie alongside one another; twisting begins and continues until double spirals are produced. The twisting of a number of filaments can be followed in consecutive photographs (Pls. 1 and 2, figs. 1-10), taken at intervals of $25 \mathrm{~min}$. The topmost filament, out of focus in the first figure, but in focus in the second one, started to twist (Pl. 1, fig. 2) and other bent filaments (Pls. 1 and 2, figs. 3-8) did likewise. In the next stage after $5 \mathrm{hr} .25 \mathrm{~min}$. the longest of the double spirals became deformed and started to break up (Pl. 2, fig. 9). Twenty-five minutes later the 
contents of the cells flowed out of their boundaries and spread over the agar surface (Pl. 2, fig. 10). I assurne that at this stage cell elements unite with each other and that the row of soft, shapeless forms which replace the double spiral is a chain of L-bodies. This peculiar mode of $\mathbf{L}$-form production in MoraxAxenfeld 260 is seen in a further developed stage in Pl. 2, fig. 12. The illustration shows large single bodies separated from each other, but showing by their arrangement their origin from twists. Twisting does not always precede L-form production. Sometimes the production of loops, convolutions or skeins seems to serve the same purpose, bringing different filaments into close contact with each other, so that fusion of cell elements can take place. Before the appearance of $\mathbf{L}$-forms small granular elements invariably develop, which are seen within the bacterial filament or become free. Granules are also often seen sticking to filaments. In Pl. 2, fig. 11 and Pl. 3, fig. 13, a number of such granules can be detected in two similar microscopical fields from a phase contrast and stained preparation respectively. Some of the L-bodies here already developed have probably not formed from double spirals but may have been produced by fusion of granular elements. Further research will be necessary to clear up the actual mode of fusion, but I think it will be found that small elements play a most important part in this process.

As incubation proceeds whole areas of growth are transformed into Lelements (Pl. 3, fig. 14); but after another 12 to $18 \mathrm{hr}$. the L-bodies revert to bacilli as in Pl. 3, fig. 15, where traces of the loose open pattern of the previous L-growth can still be detected underneath the bacillary filaments. Granules belonging to the L-phase are also present.

\section{Shigella shigae strain $K I R$}

The reversion from L-phase to bacillary form has also been studied in this rough Shigella strain. In Pl. 3, fig. 16, the bacillus is completely in the $\mathbf{L}$-form, and fig. 17 shows the bacillary chains derived from the L-form after another $12 \mathrm{hr}$. incubation. Here, too, the open lacy pattern of the original L-growth can still be discerned.

\section{Proteus vulgaris}

$P$. vulgaris readily goes into the $\mathbf{L}$-stage when the temperature is lowered appreciably. Preparations were made of the swarming edge of 15-18 hr. cultures on nutrient agar. When the cultures were cooled to $4^{\circ}$ some of the long filamentous swarmers (Pl. 3, fig. 18), of which the edge of the growth consisted, started a new development. They became less dense, and looked 'faded' both under the phase microscope and after staining. Eventually these filaments broke up into small granular elements (PI. 3, figs. 19, 20). After $1 \mathrm{hr}$. in the cold there were many granules (Pl. 4, fig. 21) which increased in numbers the longer the cultures remained in the cold. The granules are indeed remarkable, and it should be noted that the diameter of the smallest of them is much less than the width of the ordinary proteus cell.

As has been previously suggested (Klieneberger-Nobel, 1949a) two or perhaps more of the small elements may fuse, although the process has not 
yet been observed. However, at this stage the shapes of the elements are so suggestive that $I$ am convinced that fusion may be a justifiable interpretation. For example, in the upper part of Pl. 4, fig. 22, twisted filaments can be seen which look very much like the precursors of the 'fused twists' in the lower part of the same illustration. Suggestive are also the small formations indicated by the arrows in Pl. 4, fig. 21, which are seen between the dark bacillary filaments. Like the granules they are lying on the faded bacillary filaments, but they are larger and some of them are dark, others are pale. From observations it is known that they are rapidly going to develop into L-bodies.

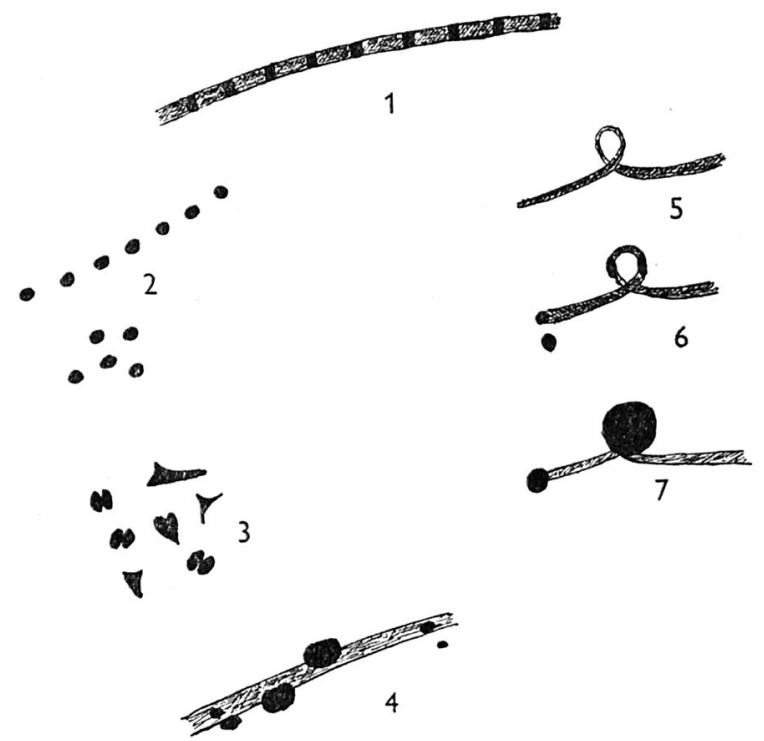

Fig. 1. Schematic diagram of the formation of L-bodies from bacillary forms.

In Fig. 1 the hypothetical formation of L-bodies is illustrated. A bacillary chain (1) breaks up into granules (1 and 2). These fuse (3) and develop into L-bodies either free or in connexion with a bacillus (4) or the bacillary chain forms a loop (5) which produces granules in the loop or at the tip of the filament (6), which may develop into bodies (7). As seen in Pl. 4, figs. 23 and 24, most of the developing bodies are lying free, but if they are connected with bacilli they are either situated at the very tips where previously granules were observed or they are found on the inside of the curved bacillary filaments where they were probably produced by loops. Of course, if they grow up from granules which stuck to a bacillus they may well simulate swollen bacilli.

With longer exposure to cold more granular forms, and bodies of various sizes which grow from the presumably fused granules, appear. Pl. 4, fig. 23, illustrates a typical 'swarming edge' that was kept in the cold overnight. The bodies are dense in these early stages, and some of them stand out almost jetblack under the phase microscope. A similar field from a stained specimen is seen in Pl. 4, fig. 24. Apart from granules and bodies of various sizes the darkly 
stained normal bacillary filaments and the faded filaments which give rise to more and more granules can be well distinguished in this illustration.

When at the stage depicted in Pl. 4, figs. 23 and 24 the cultures are reincubated at $32^{\circ}$ the still untransformed swarmers become vigorously motile. This proves that the cultures have not been killed by the cold; they form a new edge by 'swarming' according to their peculiar and most fascinating pattern. The granules and bodies immediately increase in size and decrease in density. These bodies are readily deformed when pushed by an actively motile swarmer indicating that they are very soft; they have no motility of their own. After a few hours, some of the now very big bodies (Pl. 4, fig. 25, phase contrast) divide into smaller ones by a process of segmentation. These latter bodies may grow up again and form small groups consisting entirely of L-elements which shows that they are able to grow and multiply independently. When incubation is further continued, the L-bodies form points and tapers and develop into peculiar often amoeboid shapes. At the same time they become denser and start on a process of continuous subdivision into smaller and thinner forms (Pl. 4, figs. 26 and 27, phase contrast). The L-forms are on their way to transform into bacilli. At this stage 'branching' is very often simulated as illustrated in Pl. 5, fig. 28 (stained preparation). The same phenomenon has been illustrated and described by Fleming, Voureka, Kramer \& Hughes (1950). Bacillary endings of complex forms (indicated by arrow in fig. 28) become motile again, and if they still carry about a globular part they may present a most fantastic sight. When the subdivision and transformation is complete the short young forms and not the long, swarming filaments are produced (Klieneberger-Nobel, 1947). Thus the life cycle is complete; the young forms produce the swarming cells after 3-4 hr. on a new medium. The swarmers, if exposed to the cold, produce the L-forms by breaking up into small elements which after a process of presumed fusion grow up into the big bodies. The $\mathbf{L}$-form is capable of independent multiplication, but usually reverts into the bacillary stage.

\section{DISCUSSION}

From the material presented there is indication that L-phase production is often preceded by special characteristic configurations of the elements of the culture. One particular way is the formation of double spirals which brings two different cells into juxtaposition. This occurred frequently in the MoraxAxenfeld and in Streptobacillus moniliformis and sometimes in Proteus vulgaris and other Gram-negative bacteria. Developments also occurring at this stage are formation of loops, convolutions and skeins. It is postulated that the appearance of these growth forms is followed by a fusion of small constituent elements which thus have been brought together. Whenever these configurations were observed, L-forms arose soon afterwards in their place, and at the same time the double spirals, loops and convolutions disappeared. Yet there seems to be another way of bringing together the small elements for fusion; they may be freed when the mother filaments fade and disintegrate. This happened to a large extent in $\boldsymbol{P}$. vulgaris. The L-forms produced from looping or twisting filaments are therefore more often found in connexion with the bacilli, while 
those produced from disintegrating filaments are more often observed independently. More work will be necessary to unravel completely the mode of L-form production. However, the material presented will, it is hoped, give direction to future investigations.

Some organisms go through the L-cycle and revert into the bacterial stage each time they grow. S. moniliformis and Fusiformis necrophorus belong to this group of microbes. Slightly adverse conditions seem to stimulate other organisms to go through their L-cycle (Klieneberger-Nobel, 1951). These stimuli retard the multiplication rate at a state of vigorous growth, creating a disturbance to which the organism reacts by transforming into the L-phase, in which it can withstand the adverse conditions. When the bacterial phase is newly produced from the $\mathbf{L}$-phase it is often found that new races have arisen better adapted to the adverse conditions than the mother organism. The L-cycle may therefore be regarded as a process of regeneration, initiated by a fusion of certain elements.

The bacillary cells differ from the L-stage in the following respects. The bacterium has a rigid form, and the elements of the L-phase are soft and consequently vary widely in shapes and sizes; Pl. 5, figs. 29, 30, show the stabilized L-forms of $\boldsymbol{F}$. necrophorus (phase contrast) and $\boldsymbol{S}$. moniliformis (stained) respectively. Secondly, bacteria divide by binary fission, and the L-bodies multiply by segmentation and eventually break up into small granules which germinate again and which in $S$. moniliformis are filterable through membranes that retain the smallest bacteria (Klieneberger-Nobel, $1949 b$ ). The L-stage also differs from the bacterial stage in respect of food requirements and metabolism. There are serological differences and very possibly great differences in regard to pathogenicity.

I should like to emphasize that the organization of the L-phase is similar in many important aspects to that of the pleuropneumonia-like organisms. For here we find the same shapelessness and softness and most important, the breaking into fertile granular elements of approximately the same size and filterability.

There have been many investigators who postulated a complex life cycle and reported similar observations and offered similar interpretations. I have discussed their work and the pertinent literature in a recent review (Klieneberger-Nobel, 1951).

\section{REFERENCES}

Fleming, A., Voureka, A., Kramer, I. R. H. \& Hughes, W. H. (1950). The morphology and motility of Proteus vulgaris and other organisms cultured in the presence of penicillin. J. gen. Microbiol. 4, 257.

Gondon, J. \& Gondon, M. (1943). Involution forms of the genus Vibrio produced by glycine. J. Path. Bact. 55, 63.

Klieneberger-Nobel, E. (1947). Morphological appearances of various stages in B. proteus and coli. J. Hyg., Camb., 45, 410.

Klieneberger-Nobel, E. (1949 $a$ ). Origin, development and significance of L-forms in bacterial cultures. J. gen. Microbiol. 3, 434.

KLIENEBERGER-NOBEL, E. (1949 $\mathrm{b})$. On Streptobacillus moniliformis and the filtrability of its L-form. J. Hyg., Camb., 47, 393. 
KLieneberger-Nobel, E. (1950). Methods for the study of the cytology of bacteria and pleuropneumonia-like organisms. Quart. J. micr. Sci. 91, 340.

KiIeneberger-Nobel, E. (1951). Filterable forms of bacteria. Bact. Rev. (in the Press).

\section{EXPLANATION OF PLATES}

Figs. 1-12, 14-19, 23, 25-27, 29. Phase contrast. Figs. 13, 20-22, 24, 28, 30. Fixed and stained.

\section{(Magnification $\times 2200$ throughout.)}

Figs. 1-15. Morax-Axenfeld bacillus on serum agar plus 0.05-0.07\% of glycine. Figs. 1-10. The production of L-bodies by double spirals. Fig. 1 was taken after $2 \mathrm{hr}$. of incubation; the subsequent photographs were taken at intervals of $25 \mathrm{~min}$. Fig. 11. L-bodies and granules on filaments. Fig. 12. Double spirals transforming into L-bodies. Fig. 13. L-bodies and granules stained. Fig. 14. Groups of L-bodies which had developed after $24 \mathrm{hr}$. of incubation. Fig. 15. After several days' incubation, long bacillary filaments have arisen from L-growth.

Figs. 16, 17. Sh. shigae 'KIR' on serum agar plus $0.4 \%$ glycine. Fig. 16. After $7 \frac{1}{2}$ hr. at $32^{\circ}$ and $13 \mathrm{hr}$. at room temperature. The photographed area shows L-growth exclusively. Fig. 17. The culture in fig. 16 after additional incubation at $32^{\circ}$ for $6 \mathrm{hr}$. Bacillary filaments have redeveloped.

Figs. 18-28. P. vulgaris on nutrient agar. Fig. 18. Swarming edge. Fig. 19. Part of swarming edge kept in the cold for $4 \mathrm{hr}$. A broken-up filament with granules is seen. Fig. 20. Part of swarming edge kept in the cold for $1 \frac{1}{2} \mathrm{hr}$. Bacillary filaments broken up into granules are seen. Robinow's staining method for nuclear structures. Fig. 21. Part of swarming edge kept in the cold for $1 \frac{1}{2} \mathrm{hr}$. Notice the granular elements. Fixed with osmic acid vapours and stained with Giemsa solution. Fig. 22. Swarming edge after $1 \frac{1}{2} \mathrm{hr}$. in the cold. In the upper part of the photograph a few double spirals are seen which correspond to 'fused double spirals' in the lower part of the field. Bouin Giemsa method. Fig. 23. Swarming edge kept in the cold overnight. Fig. 24. Swarming edge kept in the cold overnight. Bouin Giemsa preparation. Fig. 25. Swarming edge kept in the cold overnight and reincubated for $3 \mathrm{hr}$. The L-bodies have grown considerably and have become irregular. Fig. 26. The same as fig. 25, but $4 \mathrm{hr}$. of reincubation. Subdivision of the bodies, which are on their way to reproduce bacilli, is progressing. Fig. 27. The same as figs. 25 and 26, but $6 \mathrm{hr}$. of reincubation. Subdivision and redevelopment of bacteria has still further progressed. Fig. 28. Redevelopment of bacteria from $L$-forms. At the bottom is seen a huge branched form. At the top young bacilli are seen in a group. Bouin Giemsa preparation.

Fig. 29. L 'Fair' (pure L strain from $F$. necrophorus isolated in 1949) grown in semi-solid medium for 3 days. Bodies and droplets of a cholesterol-like material are to be seen. Fig. 30. L 1 'An' (pure L strain from $S$. moniliformis isolated in 1949) grown on serum agar for 2 days. Large amoeboid forms containing granular matter are to be seen. Bouin Giemsa preparation.

(Received 2 January 1951) 
Journal of General Microbiology, Vol. 5, No. 3
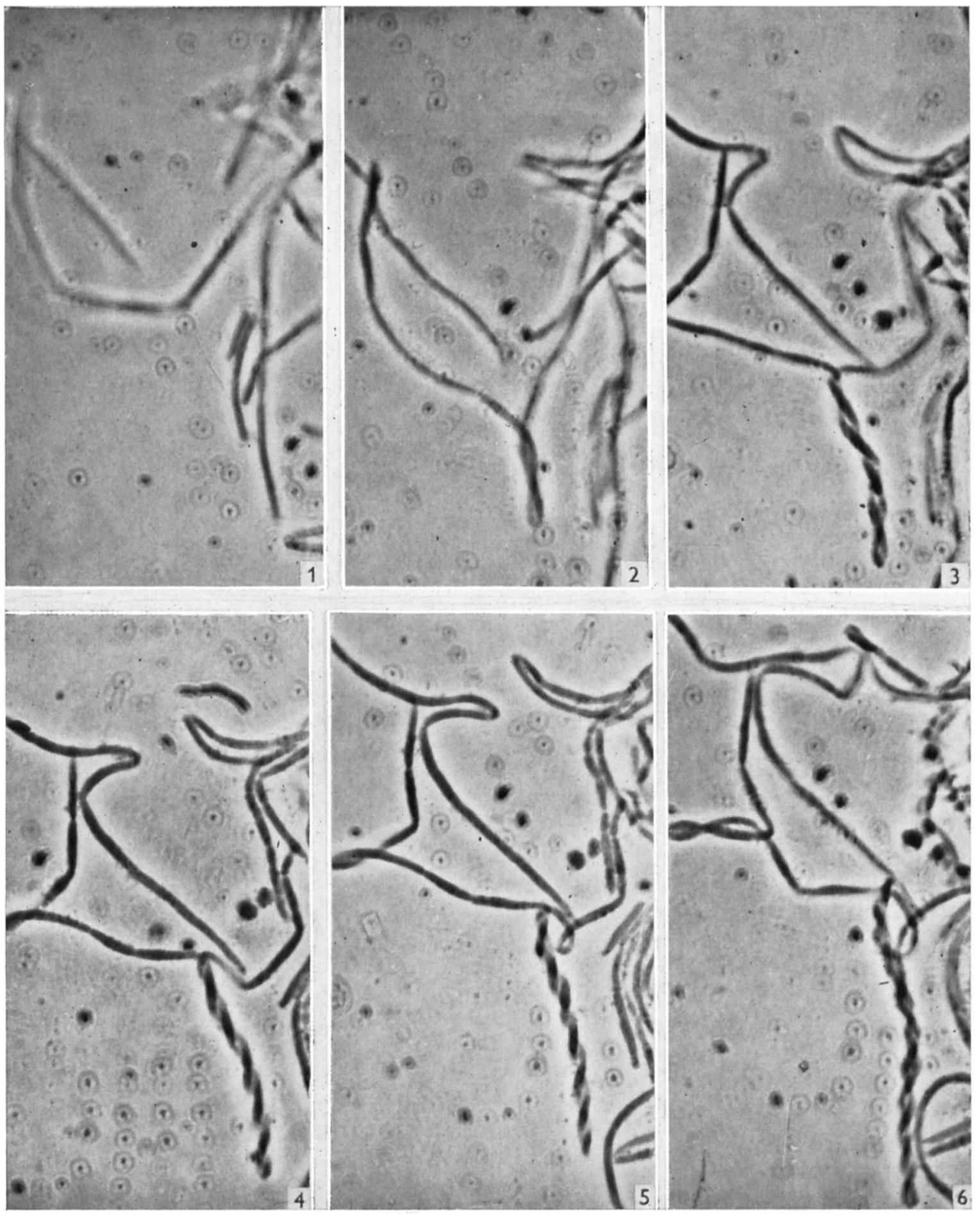

Figs. 1-6

E. Klieneberger-Nobel-The L-Cycle in bacteria. Plate 1 
Journal of General Microbiology, Vol. 5, No. 3
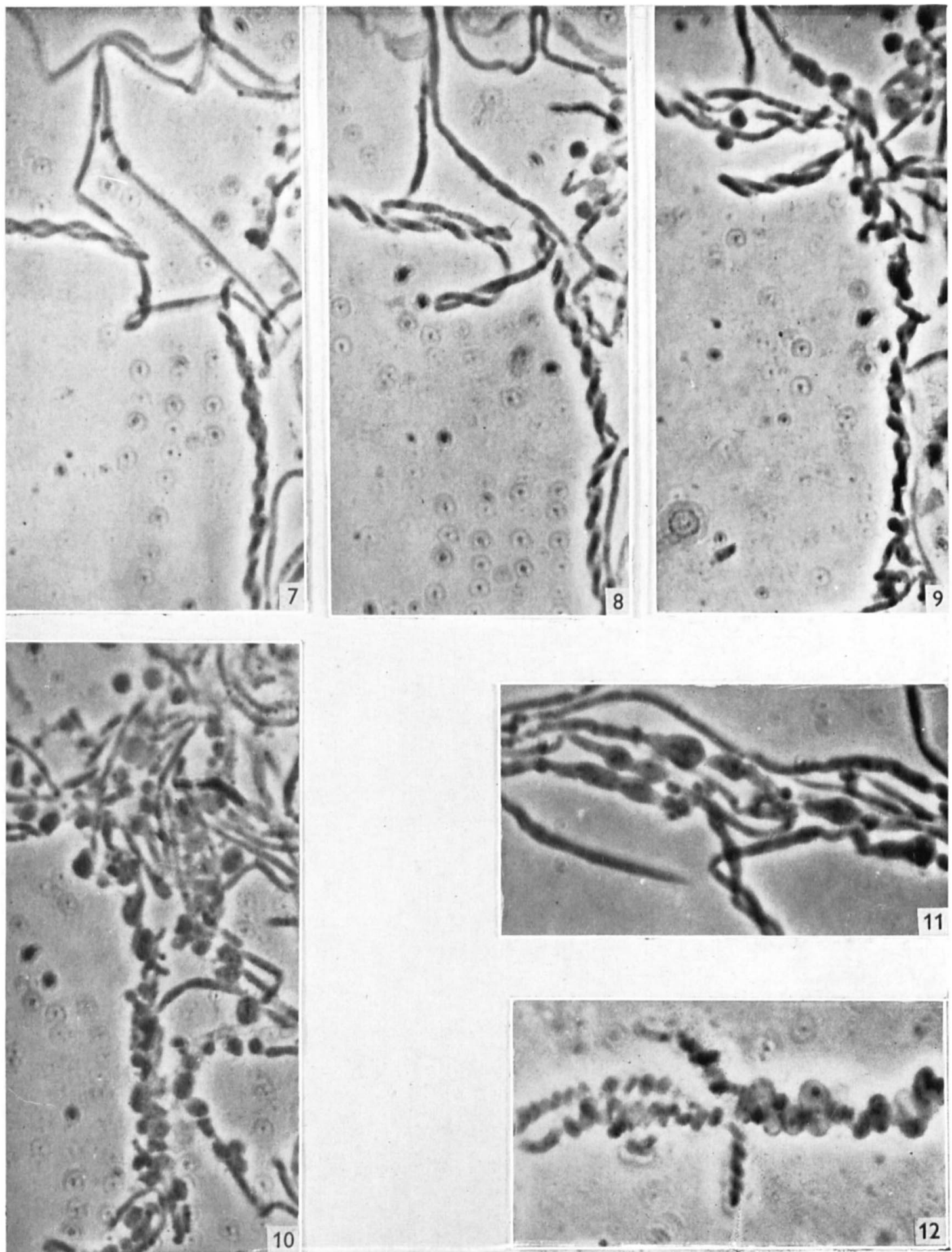

Figs. 7-12

E. Klifeneberger-Nobel--The L-cycle in bacteria. Plate 2 
Journal of General Microbiology, Vol. 5, No. 3
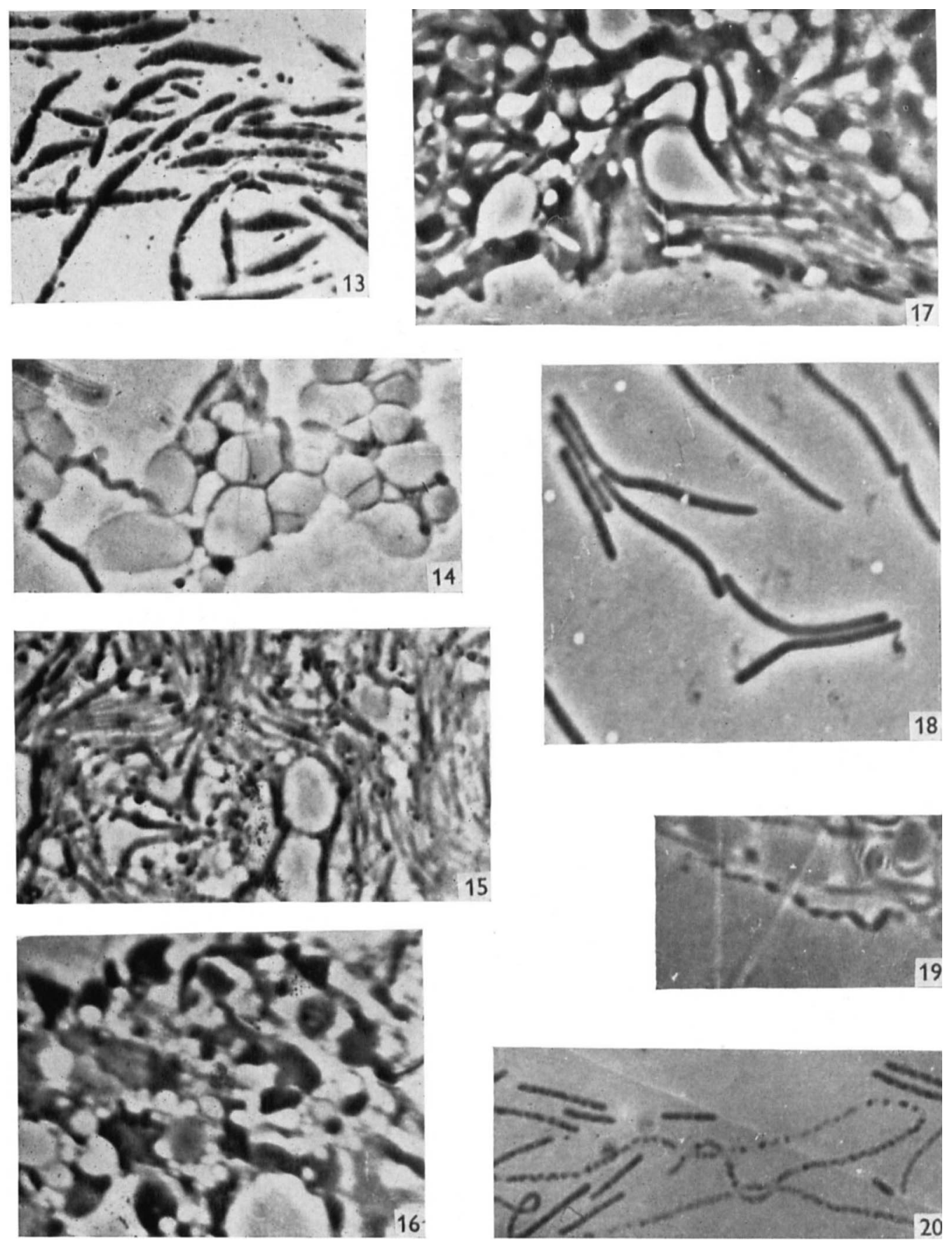

Figs. 13 20

E. Klieneberger-Nobel-The L-Cycle in bacteria. Plate 3 
Journal of General Microbiology, Vol. 5, No. 3
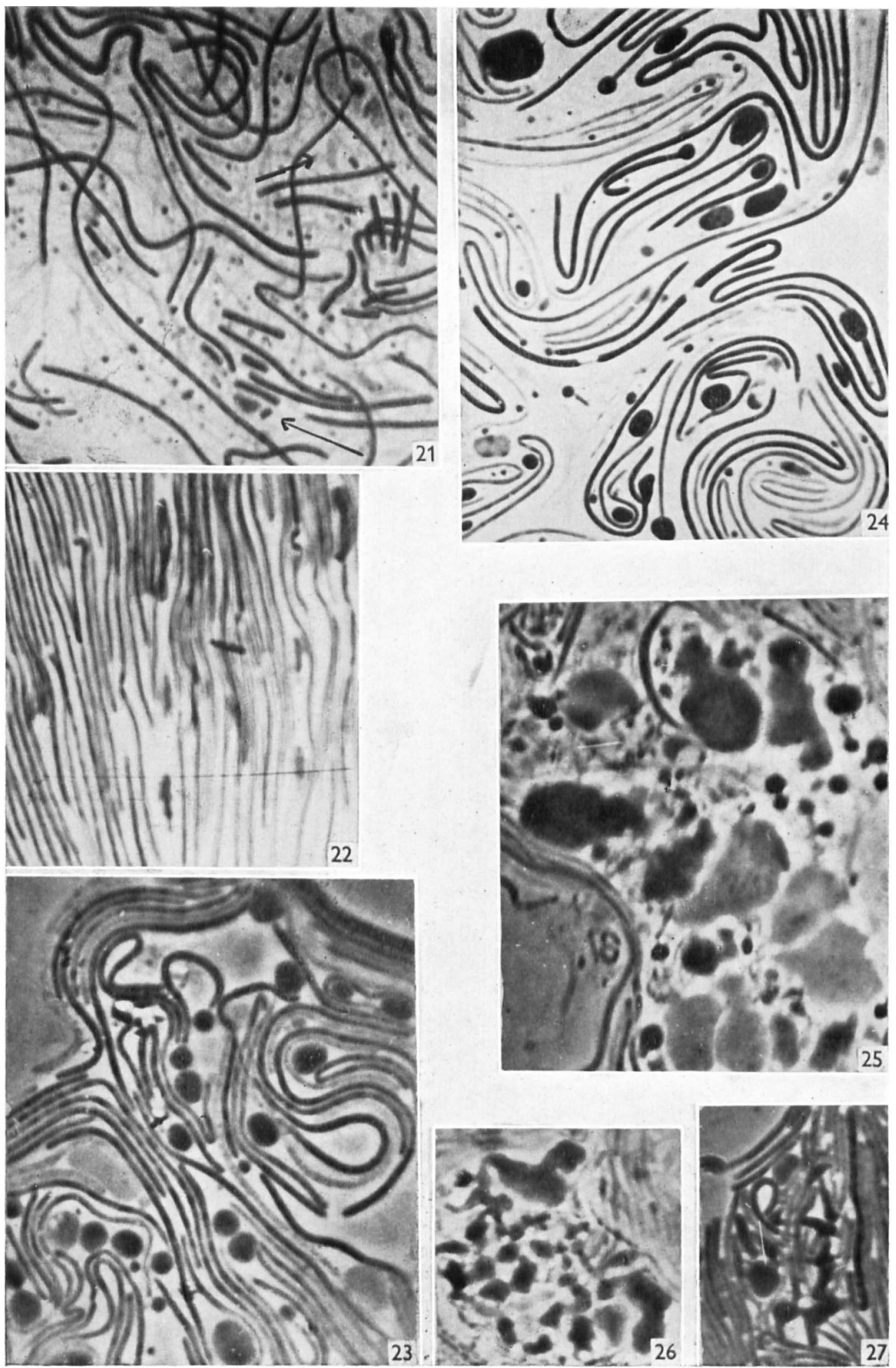

Figs. 21-27

E. Klieneberger-Nobel-The L-cycle in bacteria. Plate 4 
Journal of General Microbiology, Vol. 5, No. 3
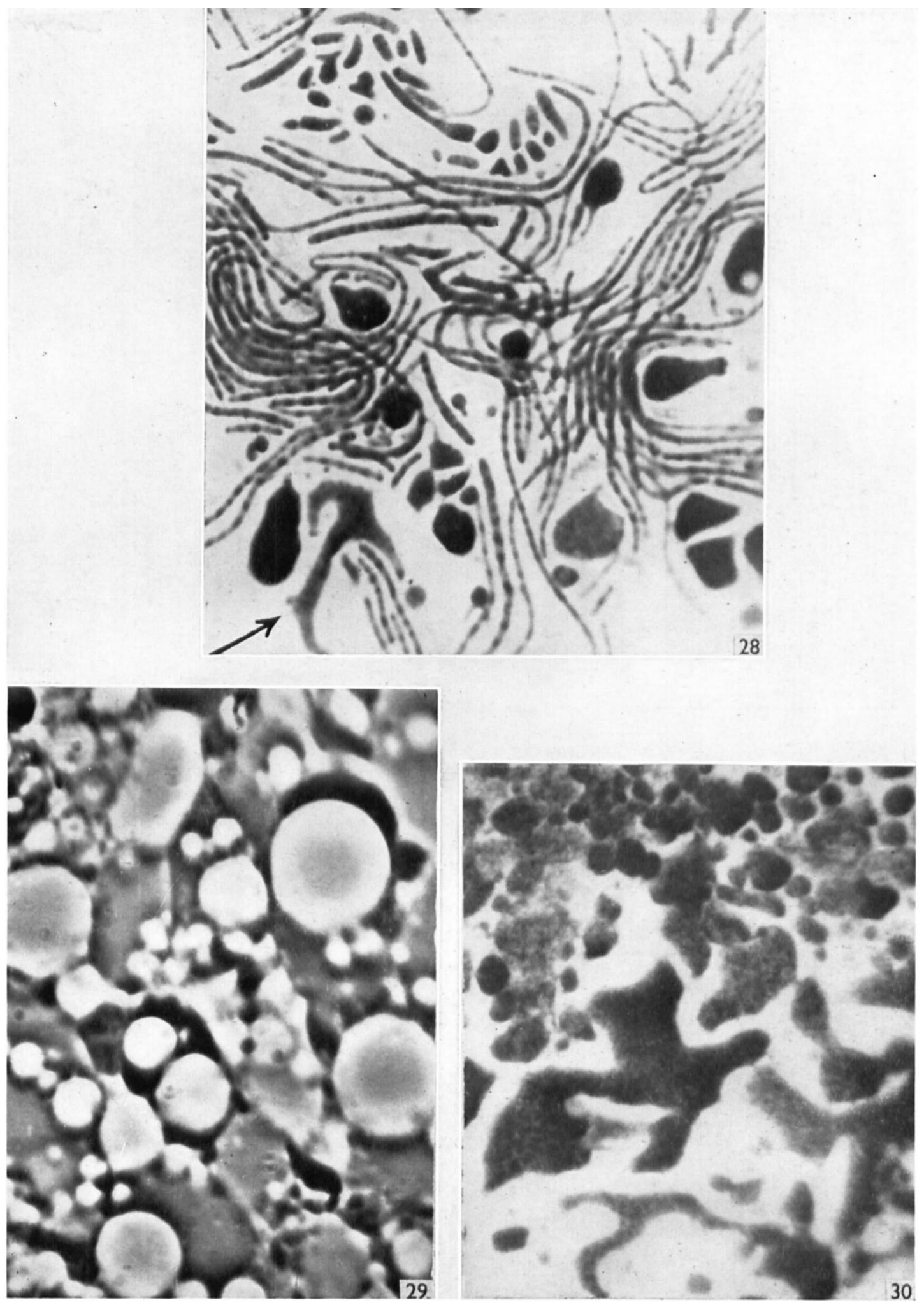

Figs. 28-30

E. Klieneberger-Nobel-The L-Cycle in bacteria. Plate 5 